\title{
Questões políticas da ditadura brasileira sob o prisma da irreverência nos Dzi Croquetes e no Teatro Besteirol
}

Luís Francisco Wasilewski ${ }^{1}$

\begin{abstract}
This paper analyses how political issues appears in performances of Dzi Croquettes, Brazilian tanztheater group, and its relation to Besteirol movement in 80 's, when the system changes from dictatorship to democratization.
\end{abstract}

Keywords: Dzi Croquettes; Brazilian drama; humor; Brazilian Nonsense Theater.

Resumo: Este artigo faz uma análise de como a questão política esteve presente nas encenações do grupo de teatro-dança brasileiro Dzi Croquettes e a relação com o movimento Besteirol dos anos 1980, durante a mudança do sistema político no país, do regime militar para a redemocratização. São analisados textos como TV Croquette Canal Dzi, $\dot{A}$ direita do presidente, Nada e Brasil, a peça. As comédias tecem uma crítica à política brasileira do período.

Palavras-chave: Dzi Croquettes; teatro brasileiro; Teatro Besteirol; humor.

\section{Considerações iniciais}

O presente estudo versará sobre como a questão política aparece sob o traço da irreverência em um texto do grupo Dzi Croquettes (uma das manifestações artísticas brasileiras mais importantes da década de 70) e em comédias escritas na década de 1980 pelos dramaturgos Mauro Rasi, Vicente Pereira, Felipe Pinheiro e Pedro Cardoso.

\section{Sobre os Dzi Croquettes}

O Dzi Croquettes surgiu na cena brasileira no ano de 1972. O projeto de formação foi engendrado pelo ator e autor Wagner Ribeiro. Foi ele também quem batizou o grupo, um trocadilho com o nome da trupe hippie e gay norte-americana The Cockettes. Os Dzi Croquettes acabam revolucionando a estética teatral brasileira e além: o trabalho obtém reconhecimento até na França. O legado do grupo está registrado no documentário homônimo sobre o grupo, dirigido por Tatiana Issa e Raphael Alvarez no ano de 2009.

\section{A mágica dos Dzi}

É neste universo que o trabalho dos Dzi Croquettes vai se inserir. Fazendo um largo uso do travestimento feminino, buscando - este era o mote da companhia - "unir a for-

1 Pós-doutorando no Programa Avançado de Cultura Contemporânea da UFRJ. Doutor em Literatura Brasileira pela USP. 
ça do macho com a graça da fêmea"2. Os integrantes eram assumidamente gays, o que fez o Dzi Croquettes ser considerado a primeira manifestação teatral brasileira na qual a questão de gênero relacionada à homossexualidade transparecia na estética dos espetáculos. Não que o travestimento feminino fosse uma grande novidade teatral no Brasil. Anteriormente, $\mathrm{O}$ Teatro de Revista se notabilizou por usar entre os seus recursos teatrais a presença de travestis nos espetáculos. O mais célebre deles, sem sombra de dúvida, foi o francês Ivaná, trazido para o Brasil pelo empresário do Teatro de Revista, Walter Pinto, em meados de 1950.

No entanto, havia uma diferença estética e ideológica entre o travestimento advindo do Teatro de Revista e o praticado pelos Dzi Croquettes. Enquanto as travestis oriundas da Revista buscavam o daguerreotipia feminina, os "croquetes" criavam um estranho travestimento em seus espetáculos. Estranho porque eles não almejavam um retrato fiel da figura da mulher. Eles se travestiam, mas também deixavam barbas à mostra, e as pernas, peludas. Era um travestimento construído a partir do contraste entre as figuras do macho e da fêmea.

No livro de Rosemary Lobert (2010, p. 20) é explicado como Wagner Ribeiro criou o nome Dzi Croquettes. Nas palavras do próprio Wagner: "Eu sempre curti muito o pronome inglês the, também poderia ser o zê português. E como a gente no bar comia croquetes, porque não batizar o grupo Dzi Croquettes".

O núcleo criador do grupo era formado por Wagner Ribeiro, Cláudio Gaya, Benedictus Lacerda, Rogério de Poly, Reginaldo de Poly, Ciro Barcelos, Paulo Bacellar e Bayard Tonelli. Os oito artistas têm aula de dança com o bailarino e coreógrafo norte-americano Lennie Dale. Leonardo La Ponzina, cujo nome artístico era Lennie Dale, havia sido um bailarino de grande sucesso na Broadway. Ele participou de musicais de sucesso como West Side Story, de Arthur Laurents. Lennie acaba se integrando aos Dzi Croquettes. Além dele, entram para a companhia Cláudio Tovar, Roberto Rodrigues, Carlinhos Machado e Eloy Simões. A formação mais conhecida teve estes treze integrantes.

Este é o elenco que se apresenta na bem-sucedida temporada do espetáculo, no Teatro Treze de Maio, na São Paulo de 1973. O nome do espetáculo era Gente Computada Igual a Você. O título foi retirado de uma das primeiras frases ditas por uma das personagens:

Nem senhores, nem senhoras

Gente dali, gente daqui

Nós não somos homens, também não somos mulheres

Nós somos gente (...) gente computada igual a você

Vocês querem uma flor, nós temos

Vocês querem uma porrada, nós também temos (LOBERT, 2010, p. 48-49).

"Nem homem, nem mulher, gente" acabou sendo um dos motes pelo qual o grupo ficou conhecido. Os Dzi Croquettes foram responsáveis por introduzir a androginia no teatro brasileiro. Uma profusão de purpurina, plumas e glitter aparecia em cena.

Lobert (1979, p. 49) faz uma descrição do quadro de abertura de Gente Computada Igual a Você. Fala também do aspecto andrógino e da indiferenciação entre o masculino e o feminino que havia na caracterização das personagens:

2 A frase era usada pelo grupo e tornou-se um de seus mais recorrentes símbolos.

94 - Conexão Letras, Porto Alegre, v. 13, n. 20, p. 93-102, jul.-dez. 2018. 
Numa explosão de música, gritos, luzes que piscam, corridas de cima para baixo, o palco é invadido de 'odaliscas, vedetes, viúvas, pierrôs, prostitutas clowns e rumbeiras': a família Dzi Croquettes se apresenta. Maquilagem, roupas e gestos os distinguem uns dos outros. Mas a indiferenciação de protótipos masculinos e femininos é comum a todos. Grandes cílios, bocas exageradas e a purpurina cintilante e colorida, formando desenhos psicodélicos, mancham seus rostos e corpos que exibem barbas, bigodes, suiças e pelos viris.

É com Gente computada igual a você que a companhia faz a sua bem-sucedida temporada francesa. Em Paris, o grupo tem como madrinha a atriz e cantora americana Liza Minnelli.

Logo após a temporada na França, ocorre a dissolução de uma parte do grupo. Lennie Dale decidiu largar a companhia. Passam a integrar a trupe Fernando Pinto, Jorge Fernando e José Paulo Corrêa. Esses nomes e mais uma parte da formação original da companhia estreiam o espetáculo Romance.

A encenação seguinte é a que coincide temporalmente com o aparecimento na mídia carioca do rótulo Besteirol. Trata-se de TV Croquette Canal Dzi, derradeiro trabalho do grupo. Era o ano de 1980. O roteiro do espetáculo foi escrito por Cláudio Gaya, Fernando Pinto e Wagner Ribeiro. O mote da peça era uma paródia da programação televisiva da época.

Há uma passagem em que a apresentadora faz um deboche sobre o patrulhamento esquerdista. Ela diz sobre a exibição dos dois filmes no canal:

Apresentadora - Hoje com dois filmes... Um estrangeiro e, para prestigiar, porque somos engajadas, um curta nacional (GAYA et al., p. 1).

É por este contexto histórico que os Dzi passarão. Uma recusa à alegria que tachará de alienada qualquer forma de contestação ao regime militar que se valha do humor. Por isso, o deboche da apresentadora em TV Croquette Canal Dzi ao dizer "porque somos engajadas". Era uma resposta ao patrulhamento esquerdista, que não via com bons olhos o humor na cena teatral. Quando dá prosseguimento às apresentações das atrações do programa, é feita uma contextualização política da época em que se passa o espetáculo:

Apresentadora - No ar, dentro de alguns instantes, a grande controvérsia do momento. Psicóloga formada pela Sorbonne... com curso de Pós-graduação na Rússia, Iugoslávia, Tchecoslováquia e Bélgica. Honoris causa em Praga. Indicada várias vezes para o Prêmio Nobel a nível de pesquisa... cognominada, devido as insofismáveis teses nunca dantes comprovadas de "A coruja de Haia”... Iniciada nos mistérios da Heleusis e recém expulsa da Alemanha Oriental... Volta ao Brasil graças a anistia (obrigada João) pois assim poderemos tê-la em nossa emissora e... em sua casa... Ela aqui está para nos elucidar alguns pontos básicos sobre as conotações contemporâneas dos problemas da criança moderna no habitat urbano atual. Com vocês... Nesse instante momento... A coruja de Haia (GAYA et al. p. 2).

A Apresentadora faz referência à anistia política dada pelo então mandatário do Brasil, João Baptista de Oliveira Figueiredo. Foi durante o governo de Figueiredo que os cassados pelo regime militar puderam voltar para o país.

O legado do grupo como fenômeno representativo do teatro musical brasileiro é recuperado em um artigo de Tânia Brandão (2010. p.31), que comenta as intervenções artísticas da época e a importância histórica do grupo, bem como assume a ideia de que eles foram, a seu modo, combativos à ditadura militar brasileira. Diz a pesquisadora: 
De certa forma, a sacudida fora anunciada por algumas intervenções importantes. A primeira foi o aparecimento do vulcânico grupo Dzi Croquettes, criadores em 1972 do espetáculo Gente computada igual a você, concebido a partir de um show de boate, em que se projetaram os nomes do coreógrafo Lennie Dale, do autor Wagner Ribeiro de Souza, e dos bailarinos Cláudio Gaya, Cláudio Tovar, Ciro Barcelos, Reginaldo de Poli, Bayard Tonelli, Rogério de Poli, Paulo Bacellar, Benedictus Lacerda, Carlinhos Machado e Eloy Simões. A irreverência do conjunto foi um acontecimento no Brasil; inspirados pelos americanos The Croquettes (sic), pelo movimento gay, pela irritação diante dos limites impostos pelos governos militares, o grupo marcou época e chegou a conquistar projeção no exterior. A cena que trouxeram foi marcada por um dado de grande relevância, a extrema liberdade de expressão dos corpos e a liberdade para olhar o mundo.

Na mesma leva irreverente e contracultural instaura-se o Teatro Besteirol, que vai apresentar um trabalho mais preocupado com a escrita e com o enredo das peças.

\section{O Teatro Besteirol}

No mesmo ano de 1980, estreava no Rio de Janeiro, no Teatro do BNH, As nil e uma encarnações de Pompeu Loredo, comédia musical de Mauro Rasi e Vicente Pereira, que recebeu a direção de um dos "croquettes", Jorge Fernando. Quem assinava a cenografia e os figurinos da montagem era outro "croquette", Cláudio Tovar. As músicas foram compostas por Eduardo Dussek e Luiz Carlos Góes. Encabeçando o elenco de Pompeu Loredo estava Duse Naccarati, antes considerada musa dos Dzi Croquettes mas que passaria a ser conhecida como "a soberana da comédia", epíteto que lhe foi conferido por Miguel Falabella. Na trama de As mil e uma encarnações de Pompeu Loredo, um funcionário público desiludido tenta matar-se. Eis que ele é socorrido pela terapeuta Neme Maluf (papel de Duse), que o convence a fazer uma sessão de regressão, e o faz descobrir que nesta encarnação ele está pagando um carma. Nesse processo, ele descobre ter sido uma falsa deusa no Egito antigo, um vampiro faminto na Transilvânia e um cardeal corrupto na Itália renascentista. Foi na crítica escrita para a "Revista Istoé" sobre esse espetáculo que Macksen Luiz colocou na imprensa pela primeira vez o termo Besteirol aplicado a um espetáculo teatral. O jornalista escreveu:

A melhor definição para a peça pode ser resumida num neologismo carioca, gíria de praia, que significa exatamente aquilo que a palavra resume: Besteirol. Essa divertida bobagem deve conseguir grande sucesso de público (BRYAN, 2004. p. 24).

Na peça temos uma alusão ao regime militar que governava no Brasil e cerceava as liberdades individuais. Trata-se de um diálogo da personagem Doutora Neme com Pompeu no começo do texto, em que Neme explica que foi impedida de exercer o seu ofício de terapeuta:

Pompeu (Preocupado) - A senhora está proibida de clinicar?

Doutora Neme - Sim. Veja que petulância das autoridades. Acho que o governo errou ao me condenar.

Pompeu (Preocupado) - Mas, proibida por quê? (Levanta-se, pronto para sair) O que foi que a senhora fez? 
Doutora Neme (Tranquilamente fazendo-o sentar-se novamente) - E é preciso fazer alguma coisa para ser punida num regime autoritário? (PEREIRA; RASI, 1980a., p. 3)

No mesmo ano de Pompeu Loredo, Mauro e Vicente tiveram encenada no Rio de Janeiro a comédia de autoria da dupla chamada $A$ direita do presidente. A peça trazia um componente novo para o teatro brasileiro, que é o fato da ação se passar em Brasília. O enredo versa sobre a amante de um importante político brasileiro que, após ter sido abandonada por ele, decide se arrumar em um salão de cabeleireiro para ir sozinha até a posse do novo presidente do Brasil.

Em algumas passagens, Leda (a amante do político) e Fúlvio (o cabeleireiro) comentam sobre a situação política do país, com alguma descrença em relação ao futuro e à democracia:

Leda (Aponta para a TV) - Olhe, a gente não vai ouvir o discurso do Presidente?

Fúlvio - Agora eu vou é colocar um disco, pra me inspirar. Só sei trabalhar com música. Não estou com um pingo de interesse no que o Presidente vai falar. Abertura, democracia. Esse papo não adianta nada (PEREIRA; RASI, 1980b., p. 15).

Em outra passagem do texto, Fúlvio e Leda recordam dos governos de Juscelino Kubitschek e João Goulart, visitando, em seus comentários, lugares comuns e antagônicos em torno das figuras dos políticos: de um lado os "pais da pátria" e, de outro, os desonestos:

Fúlvio - Melhor época prá mim foi a época do Jango. Podem falar, o que quiserem dele, mas nessa época eu não passava necessidade.

Leda - Ah, Fúlvio, na época do Juscelino também. Corria muito dinheiro.

Fúlvio - Dizem que ele roubou muito (PEREIRA; RASI, 1980b., p. 16).

A peça fala de outros temas da política brasileira da década de 60 e 70, como a perseguição aos estudantes revoltosos com o regime militar, bem como das canções de protesto que marcaram o período da ditadura militar.

Em junho de 1981 estreou no Teatro Casa Grande, no Rio de Janeiro, a comédia escrita por Mauro Rasi intitulada A receita do sucesso. Na ficha técnica do espetáculo, constavam nomes de alguns integrantes dos Dzi Croquettes, como o de Paulo Bacellar, que além de responder pela coreografia do espetáculo, integrava o elenco, assim como o de Jorge Fernando, que foi o diretor da montagem. Além dos dois citados, a cenografia do espetáculo levava a assinatura de Américo Issa, que foi cenógrafo e iluminador dos Dzi a partir do ano de 1976 até o encerramento do grupo. No elenco da peça figuravam os nomes de Vicente Pereira, Duse Naccarati, Marcus Alvisi, Vera Setta, Denise Barros, Christiane Couto, Marcelo Altomar, Frida Batist, Rose de Mello, Felipe Martins e o já citado Paulo Bacellar.

A estrutura da peça era feita de esquetes ${ }^{3}$, traço que tornar-se-á comum nas peças do Teatro Besteirol. Em um deles, chamado "A libertária", havia uma crítica ao regime militar valendo-se da comédia. O esquete mostrava o reencontro de duas amigas chamadas Nívea Maria e Dandara, que viveram juntas o desbunde da década de 70 e que se reencontram nos anos 80. Enquanto Dandara permaneceu com o comportamento libertário,

3 Segundo Patrice Pavis, em seu Dicionário de Teatro: "O esquete é uma cena curta que apresenta uma situação geralmente cômica, interpretada por um pequeno número de atores sem caracterização aprofundada ou de intriga aos saltos e insistindo nos momentos engraçados e subversivos.” (PAVIS, 2008, p.143). 
Nívea Maria se casou com um militar e tornou-se uma mulher séria e conservadora. Os diálogos entre elas colocam em exposição pensamentos opostos, bem como a aversão que Dandara sente pela figura do militar:

Nívea Maria - Você sabia que eu casei? Tenho um filhinho.

(Vão até o berço. A criança começa a chorar. Nívea pega-o no colo)

Dandara - Casou, é? É, você tinha que casar mesmo. Casou com quem?

Nívea Maria - Você não conhece. Ele é da Força Aérea.

Dandara (Horrorizada) - ... ele é militar?

Nívea Maria - Da Aeronáutica.

Dandara - E você não tem medo dele?

Nívea Maria-Medo? Ele é meu marido.

Dandara - Mas ele sabe que você já puxou fumo? Que já tomou ácido?

Nívea Maria (Pondo o bebê no berço) - Escuta aqui, Dandara... Isso foi há muito tempo.

Eu até já me esqueci. E depois, foi por causa das más companhias de gente como você...

(RASI, 2016, p. 34-35).

Em outra passagem, há mais uma crítica ao regime militar. Trata-se do momento em que Nívea Maria recebe uma homenagem do marido. A situação é ambígua e mostra dois pontos de vista opostos:

(Ouve-se barulho de avião)

Nivea - Ah, deve ser ele. (Corre para a janela e acena para o céu)

Nívea - É ele. O Glayson. (Acena, gritando) Glayson!

(Uma nuvem de fumaça entra pela janela após o avião dar um rasante. Elas tossem)

Nívea - Ele é da "Esquadrilha da Fumaça"... Olha lá o que ele escreveu lá no céu...

Dandara (Lendo, com desdém, despeitada) - "Nivea Maria, eu te amo..." (Despeitada)

Hum... Quer dizer que ele fica gastando a fumaça do povo para escrever besteira?

Nívea - Ah, eles estão no poder, né, fazem o que querem... (RASI, 2016, p. 35).

No mesmo ano de $A$ receita do sucesso, Mauro Rasi foi um dos autores de Cabaret $S / A$, montagem idealizada pelo Teatro Rival que recuperava os antigos Cabarets, bem como o Teatro de Revista. O Teatro Rival, no centro do Rio de Janeiro, foi um dos locais onde o Teatro de Revista vicejou. Seu fundador, o empresário Américo Leal, foi também um importante produtor de espetáculos do gênero. O roteiro de Cabaret $S / A$ reunia além de textos de Mauro, outros escritos por Oswald de Andrade, Grande Otelo, Flávio São Thiago, Ângela Leal (filha de Américo), Heloísa Arruda, Cláudio MacDowell, Antônio Pedro e Jorge Laclette. No elenco, destaque para a participação de Grande Otelo, um dos mais importantes cômicos das chanchadas cinematográficas e do Teatro de Revista no Brasil.

Para Cabaret $S / A$, Mauro escreveu os esquetes "A vedete que não era leviana", "Valdirene, a paranormal" (posteriormente, título de uma canção composta por Eduardo Dussek e Luiz Carlos Góes) e "Uirapuancy, a cabeça que fala". "Uirapuancy" era um deboche do dramaturgo que satirizava o universo esotérico. Uirapuancy é uma cabeça que possui o "dom de prever o futuro". Já na apresentação inicial do esquete, o autor utiliza-se do humor para descrevê-la:

Muitos são os mistérios que envolvem o Oriente, mas certamente nenhum é maior que este. Ela foi descoberta nas selvas da Birmânia, causou sensação em Bombain, Tokyo e 
Madagascar. Senhoras e Senhores é chegado o momento de apresentar vinda diretamente de Java, "Uirapuancy, a cabeça que fala" (RASI, 2016. p. 58).

Em uma passagem do esquete é feita uma menção explícita à política brasileira. Trata-se do momento em que um bêbado dialoga com Uirapuancy e pergunta sobre as próximas eleições para o governo do estado do Rio de Janeiro, no caso, a disputa eleitoral de 1982:

Bêbado - Quem vai ganhar a eleição para governador do estado do Rio?

Uirapuancy (Fulminando-o) - Minha amiga, Sandra! (E dá uma gargalhada) (RASI, 2016. p. 63).

Sandra Cavalcanti era uma política e jornalista carioca. Foi candidata ao Governo do Estado do Rio de Janeiro no ano de 1982, ano em que Cabaret $S / A$ ainda estava em cartaz. Sua trajetória política foi marcada pelo apoio ao regime militar, tendo sido deputada eleita em 1974. No pleito para o governo do Rio de Janeiro em 1982, Sandra ocupou o quarto lugar, ou seja, não cumpriu a profecia.

Referências como a citada acima fazem das peças do Teatro Besteirol um desenho de personalidades, costumes e fatos que aconteceram na década de 1980. A dupla Pedro Cardoso e Felipe Pinheiro formou-se no ano de 1982 com a encenação de Bar, doce bar, espetáculo que foi um sucesso de público e crítica em sua temporada no Teatro Candido Mendes.

Os dois estreiam, em 1988, Nada, espetáculo de esquetes, cujas algumas passagens tratam de forma humorada a política brasileira. Algo que, como já foi examinado neste estudo, é corrente tanto nos Dzi Croquettes, quanto nos precursores do Teatro Besteirol. Na primeira cena de Nada, quando o apresentador vai anunciar um concerto, é feita uma alusão cômica ao então governador do estado do Rio de Janeiro, Moreira Franco:

Apresentador - Este concerto foi escrito originalmente para piano e orquestra, mas, infelizmente, um pequeno incidente tornou impossivel a vinda da orquestra sinfônica do Teatro Municipal. O fusca que transportava a Orquestra ficou detido em Niterói, onde a OSTM participava de um comício pró Moreira Franco (CARDOSO; PINHEIRO, 1988. p. 1).

A crítica teatral Barbara Heliodora ressaltou em sua análise as virtudes da montagem e comparou o espetáculo de Pedro e Felipe, que sempre em suas encenações contaram com a participação do músico Tim Rescala, ao grupo argentino Les Luthiers, que também sempre pautou suas criações com base na comédia musical. Barbara comentou:

O que é chamado de Nada não pretende ser uma peça; trata-se de uma série de esquetes independentes, unificados apenas pelo humor. Ao longo da sequência, toda ela divertida, em alguns casos brilhantes, pode-se constatar, talvez, que desmascara e deixa exposto o cerne do tema criticado pelo ridículo. Em outros momentos, porém, o intuito de divertir por meio do absurdo, do insólito, domina tudo e o primeiro quadro, o do conserto (sic) para piano e orquestra, é - tanto pela graça quanto pela sofisticação musical - a primeira instância de um esquete nacional que pode falar de igual para igual com os notáveis Les Luthiers argentinos (HELIODORA, 2007, p. 813).

1989 foi o ano em que o Brasil comemorou o centenário da Proclamação da República. Também foi um ano emblemático pelo fato de que, após um longo período de regime 
militar, o país finalmente teve eleições diretas para presidente. A última eleição direta tinha acontecido no ano de 1960, com a vitória de Jânio Quadros. Tais fatos suscitaram a criação do espetáculo Brasil, a peça, escrito por Luiz Carlos Góes, Maria Lúcia Dahl, Miguel Falabella e Vicente Pereira. O espetáculo marcava a inauguração do Teatro do Posto 6, de propriedade da atriz Thaís Portinho, que também atuava na encenação. Os quatro autores revisitavam de forma cômica diferentes períodos da história brasileira. Maria Lúcia, por exemplo, escreveu sobre o golpe militar de 1964. Luiz Carlos tratou da abolição da escravatura, enquanto que Miguel falou da relação entre uma índia e o colonizador.

Vicente Pereira foi o dramaturgo que, em Brasil, a peça, satirizou a política brasileira da década de 1980. O título do seu esquete é "Ame-o ou deixe-o", frase que se tornou emblemática durante a ditadura militar. "Brasil, ame-o ou deixe-o" foi uma expressão ufanista criada durante o governo do presidente Emílio Garrastazu Médici, com o intuito de despertar na população brasileira o patriotismo e o apoio à ditadura militar. A gestão de Médici é vista pelos historiadores como o período mais duro da ditadura militar brasileira. Foi durante seu governo que guerrilheiros importantes no combate à ditadura, como Carlos Marighella e Carlos Lamarca, foram assassinados.

Em seu livro História concisa do Brasil, o historiador Boris Fausto (2006) faz uma descrição do governo Médici:

Para o grande público, Médici era um nome desconhecido. Além disso, não tinha gosto pelo exercício do poder, tendo delegado a seus ministros o exercício do governo. Daí resultou o paradoxo de um comando presidencial dividido em um dos periodos mais repressivos, se não o mais repressivo, da história brasileira./ Os grupos armados urbanos, que a princípio deram a impressão de desestabilizar o regime com suas ações espetaculares, declinaram e praticamente desapareceram. Esse desfecho resultou, em primeiro lugar, da eficácia da repressão, que abrangeu os ativistas da luta armada e seus simpatizantes, constituida esta última sobretudo por jovens profissionais. Outro fator foi o isolamento dos grupos da massa da população, cuja atração por suas ações foi mínima, para não dizer nenhuma (FAUSTO, 2006, p. 267).

O esquete de Vicente tem sua ação ambientada no Aeroporto do Galeão. Nele, uma estilista de moda fracassada e desiludida com os rumos que o Brasil está tomando, chamada Teodora, encontra um cantor popular de nome Lindomar Sampaio, que assassinou a esposa. A história do cantor é inspirada no caso de Lindomar Castilho, músico que assassinou a esposa Eliana de Gramond. Como o aeroporto vive em um caos aéreo, os dois não conseguem embarcar. Eles entabulam, então, um diálogo. Em um excerto do texto, Lindomar fala do seu patriotismo e de fatos históricos nos quais atuou, como a construção de Brasília e da Transamazônica:

Lindomar - A senhora está na frente de um brasileiro que tinha orgulho de ser brasileiro. Eu entrei em todas. Eu ajudei a construir Brasília. Estive na Serra Pelada. Transamazônica. Belém-Brasília. Garibaldi, no Sul... Batalhei como um condenado! Um candango. Se quiser pode me considerar um candango. Esquece a suntuosidade do traje e veja um candango maltrapilho. Esfarrapado (PEREIRA et al., 1989, p. 36).

A personagem Teodora completa Lindomar fazendo o seu desabafo a respeito dos problemas políticos enfrentados pelo Brasil, na década de 1980, como a morte do presidente Tancredo Neves: 
Teodora - Compreendo e avalio a sua dor. Deve ser terrivel o desencanto de um pioneiro. O que acaba com o povo brasileiro é a esperança. Esperar o quê? Alguma coisa que se esperou, cumpriu-se? Me responda. Angra cumpriu-se? Algum pacote economico de qualquer governo, cumpriu-se? Nossa última esperança foi-se com o velhinho. (Suspira) Chorei tanto quando ele morreu... me senti tão desamparada, tão destruída, parecia que era alguém da minha família. Cheguei a passar um telegrama prá Dona Rizoleta (Sic). (Tom) "Rizoleta não bebi de seu vinho, não comi de seu pão. Mas bebo do vinagre que lhe coube" (PEREIRA et al., 1989. p. 36).

E ela prossegue a sua lamentação:

[...] E o que eu passei nos comícios das diretas? Me esgoelei. Descabelei. Acreditei. (Tom) E o máximo que eu consegui foi um autógrafo da Lucélia Santos (PEREIRA et al., 1989. p. 36).

Teodora faz nestes excertos uma alusão à campanha de Eleições Diretas para Presidente, que ficou conhecida como Diretas Já, movimento que reuniu políticos como Fernando Henrique Cardoso, Leonel Brizola, Luiz Inácio Lula da Silva, Ulysses Guimarães e artistas como Lucélia Santos e Fafá de Belém. O resultado da mobilização foi a eleição de Tancredo Neves para Presidência da República através de um colégio eleitoral. Tancredo era o "velhinho" citado por Teodora em uma das passagens anteriores. Sua morte foi uma comoção nacional. Boris Fausto (2006, p. 285) comenta o episódio:

Com a eleição de Tancredo Neves, a transição para o regime democrático não terminou e estaria sujeita ainda a imprevistos. A posse do novo presidente, marcada para 15 de março de 1985, não ocorreu. Depois de uma viagem ao exterior, Tancredo foi internado às pressas em um hospital de Brasília, sofrendo uma primeira e discutida operação, com políticos e amigos presentes na sala de cirurgia. Nesse ínterim, Sarney subiu a rampa do Planalto, tomando posse no lugar do presidente eleito, em uma situação que se acreditava fosse transitória./Seguiu-se a agonia de Tancredo, com seu traslado para São Paulo e uma série de operações a que foi submetido. O país ficou pendente de boletins médicos, alguns dos quais alimentavam um falso otimismo. Tancredo morreu a 21 de abril, na data simbólica da morte de Tiradentes. Multidões foram às ruas para acompanhar o corpo na saída de São Paulo, na passagem por Brasília e Belo Horizonte, até o enterro em sua cidade natal. Uma parte das manifestações resultava da comoção provocada pela morte de um presidente, ainda mais em condições tão dolorosas. Mas havia também a sensação de que o país perdera uma figura política importante em um momento delicado.

Com "Ame-o ou deixe-o" Vicente, através da personagem Teodora, tematiza um problema que, com o passar do tempo, vai se agravando na sociedade brasileira. Faço referência aos brasileiros que, devido às dificuldades econômicas vividas no país, decidem ir para o exterior, na esperança de uma vida melhor.

\section{Considerações finais}

Este artigo avaliou como as questões políticas foram abordadas por um grupo de autores cômicos. Primeiramente, verificou-se brevemente como elas apareceram como tema nos Dzi Croquettes, grupo emblemático da década de 1970 que, durante a sua trajetória, foi taxado de alienado por uma parte da esquerda política. 
Também foram investigados os trabalhos que criaram a estética do Teatro Besteirol, avaliando como o coletivo de autores desse gênero teatral tematizou a política brasileira em seus textos dramáticos. Assim, ainda que não tenham elaborado um engajamento artístico declarado e intenso, os trechos das peças aqui citados comprovam que havia uma preocupação com a situação sociopolítica brasileira e, com o auxílio do humor, tanto os Dzi Croquettes quanto o Teatro Besteirol participaram ativamente e questionaram os problemas de seu tempo.

\section{Referências}

BORNHEIM, G. Páginas de filosofia da arte. Rio de Janeiro: Uapê, 1998. BRANDÃO, T. Uma cena de muitas histórias. In: RIECHE, E.; GASPARINI, G. Em busca de um teatro musical carioca. São Paulo: Imprensa Oficial do Estado de São Paulo, 2010.

BRYAN, G. Quem tem um sonho não dança: cultura jovem brasileira nos anos 80. Rio de Janeiro: Record, 2004.

CABRAL, S. Grande Otelo: uma biografia. Rio de Janeiro: Editora 34, 2007.

CARDOSO, P.; PINHEIRO, F. Nada. Rio de Janeiro: [s.n.], 1988.

FAUSTO, B. História concisa do Brasil. São Paulo: EDUSP, 2006.

FERNANDES, S. Grupos teatrais - anos 70. Campinas: Ed. da UNICAMP, 2000.

GAYA, C. et al. TV Croquette Canal Dzi. Rio de Janeiro: [s.n.], 1980.

HELIODORA, B. Escritos sobre teatro. BRAGA, C. (Org.). Perspectiva: São Paulo, 2007.

HOLLANDA, H. B. Asdrúbal trouxe o trombone: memórias de uma trupe solitária de comediantes que abalou os anos 70. Rio de Janeiro: Aeroplano, 2004.

LOBERT, R. A palavra mágica Dzi: uma resposta difícil de se perguntar - a vida cotidiana de um grupo teatral. Campinas: Editora da Unicamp, 2010.

MARINHO, F. Quem tem medo de besteirol? Rio de Janeiro: Relume Dumará, 2004.

PAVIS, P. Dicionário de Teatro. São Paulo: Perspectiva, 2008. Trad. J. Guinsburg e Maria L. Pereira.

PEREIRA, V.; RASI, M. As 1001 encarnações de Pompeu Loredo. Rio de Janeiro:

[s.n.], 1980a.

. A direita do presidente. Rio de Janeiro: [s.n.], $1980 \mathrm{~b}$.

PEREIRA, V. et al. Brasil, a peça. Rio de Janeiro: [s.n.], 1989.

RASI, M. A Receita do sucesso. In: WASILEWSKI, L. F. (Org.). Ifigênia em Sodoma e outros textos curtos. São Paulo: Giostri, 2016. p. 27-45.

RASI, M. et al. Cabaret S/A. In: WASILEWSKI, L. F. (Org.). Ifigênia em Sodoma e outros textos curtos. São Paulo: Giostri, 2016. p. 46-56. 